\title{
POLÍTICAS PÚBLICAS PARA A AGRICULTURA FAMILIAR BRASILEIRA: UM ESTUDO SOBRE $O$ PRONAF NOS MUNICÍPIOS DO CIRCUITO DAS FRUTAS-SP ${ }^{1}$
}

\author{
Vanilde Ferreira de Souza-Esquerdo ${ }^{2}$ \\ Sonia Maria Pessoa Pereira Bergamasco ${ }^{3}$
}

\section{Resumo}

No Brasil, a grande propriedade foi o modelo socialmente reconhecido, sendo as políticas públicas direcionadas a essa categoria. No período recente houve, por parte do Estado, uma tentativa de fortalecimento da agricultura familiar no que diz respeito a estímulos através de linhas de crédito rural e ampliação dos canais de comercialização, havendo o reconhecimento de sua importância. Tal reconhecimento ocorreu, inicialmente, através da formulação e implementação do Pronaf (Programa Nacional de Fortalecimento da Agricultura Familiar), que surgiu, sobretudo, por meio das diversas lutas dos trabalhadores rurais. Desde a sua implementação, em 1996, o Pronaf vem se consolidando ano a ano como o principal programa de crédito de apoio à agricultura familiar no Brasil. Percebe-se que a cada ano há um aumento tanto do número de beneficiários, quanto do montante de recursos financeiros disponibilizados e aplicados no Programa. Nesse sentido, 0 presente trabalho teve por objetivo analisar o volume de créditos e o número de contratos do Pronaf nos municípios que pertencem ao Circuito das Frutas, no São Paulo, uma vez que essa região possui presença marcante de agricultores familiares. Dentre os resultados do trabalho, realizado através do levantamento de dados secundários, percebeu-se que, diante do universo da agricultura familiar nos municípios, ainda é pequena a participação dos agricultores familiares no programa analisado.

\footnotetext{
${ }^{1}$ Este artigo faz parte do pós-doutorado da primeira autora, supervisionado pela segunda autora, intitulado: O impacto das políticas agrícolas nos municípios do Circuito das Frutas-SP, financiado pela FAPESP.

${ }^{2}$ Pesquisadora colaboradora na Feagri/Unicamp. Pós-doutoranda na Ufscar-Araras. Email: vanilde@yahoo.com

${ }^{3}$ Profa. Titular Feagri/Unicamp, bolsista produtividade em pesquisa, CNPq e bolsista do Programa Nacional de Professor Visitante Sênior (PNPVS) da Capes, junto à UFSCarAraras. E-mail: sonia@agr.unicamp.br
} 
Palavras-chave: agricultura familiar, políticas públicas, Pronaf.

\title{
PUBLIC POLICIES FOR THE BRAZILIAN FAMILY FARMING: A STUDY ON THE PRONAF IN THE MUNICIPALITIES OF THE FRUITS CIRCUIT - SP
}

\begin{abstract}
In Brazil, the large rural property was the socially recognized model, with public policies directed to this category. In the recent period, the Brazilian State has recognized the importance of family farming, trying to strengthen it through rural credit facilities and the expansion of marketing channels. Such recognition was taken place through the formulation and implementation of the Pronaf (National Program for Strengthening of Family Farming) program, which arose mainly through the farm workers' struggles. Since its establishment, in 1996, the Pronaf has become, year to year, the main public policy supporting family farming in Brazil. It has been noticed that every year there is an increase in the number of beneficiaries, as well as the amount of the available financial resources in the program. In this sense, this work aimed to analyze the volume of credit and the number of Pronaf's contracts in the municipalities of the Fruits Circuits, in the State of São Paulo, since this region has a strong presence of family farmers. The results of the work, which was carried out through the collection of secondary data, showed that, given the universe of family farming in the municipalities, it is still small the participation of the farmers in the analyzed program.
\end{abstract}

Keywords: familiy farming, public policies, Pronaf.

\section{INTRODUÇÃO}

Apresenta-se neste texto uma pesquisa sobre o Programa Nacional de Fortalecimento da Agricultura Familiar - Pronaf em 10 municípios localizados no Circuito das Frutas, no estado de São Paulo. Trata-se de uma região muito importante para a produção de frutas no estado, realizada essencialmente por agricultores familiares.

Foi feito um levantamento de informações sobre a área estudada, onde foram percebidas as tradições de imigrantes, sobretudo, europeus na produção das frutas e mesmo nas festas que 
ocorrem no Circuito das Frutas. Após essa busca de informações sobre a área de estudo, foi realizado o levantamento bibliográfico sobre o Pronaf, onde se percebeu que, a partir dos anos 1990, a agricultura familiar no Brasil começou a ter reconhecimento enquanto categoria social e produtiva, através da formulação de programas de políticas públicas a seu favor. De forma geral, pode-se dizer que até o início da década de 1990 não havia nenhum programa de política pública com abrangência nacional para os agricultores familiares.

Em meados dos anos 2000, houve a necessidade de uma definição legal sobre o termo agricultor familiar, principalmente para facilitar seu acesso aos programas de políticas públicas. Esta definição ocorreu a partir da implantação da Lei 11.326/2006. Assim, esse agricultor é aquele que pratica atividades no meio rural atendendo, simultaneamente, aos seguintes requisitos:

I - não detenha, a qualquer título, área maior do que 4 (quatro) módulos fiscais;

II - utilize predominantemente mão de obra da própria família nas atividades econômicas do seu estabelecimento ou empreendimento; III - tenha renda familiar predominantemente originada de atividades econômicas vinculadas ao próprio estabelecimento ou empreendimento;

IV - dirija seu estabelecimento ou empreendimento com a família.

A Lei 11.326/2006 estabeleceu, legalmente, a padronização do termo agricultor familiar a fim de que esses acessassem os programas direcionados a eles.

Devido à importância que a agricultura brasileira possui, seja pela manutenção do homem no campo ou pela produção de alimentos, torna-se importante compreender a dinâmica de políticas no contexto da agricultura familiar, para que assim se possa verificar os aspectos positivos e negativos referentes a elas. Nesse sentido, este trabalho objetivou analisar o volume de créditos e o número de contratos do Pronaf nos municípios que pertencem ao Circuito das Frutas, no estado de São Paulo, pelo fato dessa região possuir presença marcante de agricultores familiares. 


\section{METODOLOGIA}

\section{1 Área de Estudo}

A área escolhida para o estudo foi o Circuito das Frutas, que compreende 10 municípios com acentuada presença da agricultura familiar, principalmente para a produção de frutas e para o turismo rural. Essa área é um dos principais e melhores circuitos turísticos do estado de São Paulo. Nesse sentido, faz-se relevante também a análise dos programas de políticas públicas nesses espaços. Os municípios que fazem parte do Circuito das Frutas são: Atibaia, Indaiatuba, Itatiba, Itupeva, Jarinu, Jundiaí, Louveira, Morungaba, Valinhos e Vinhedo, que têm nas suas economias uma forte presença do setor rural, principalmente da fruticultura, com destaque para as culturas da uva, morango, pêssego, goiaba, ameixa, caqui, acerola e figo.

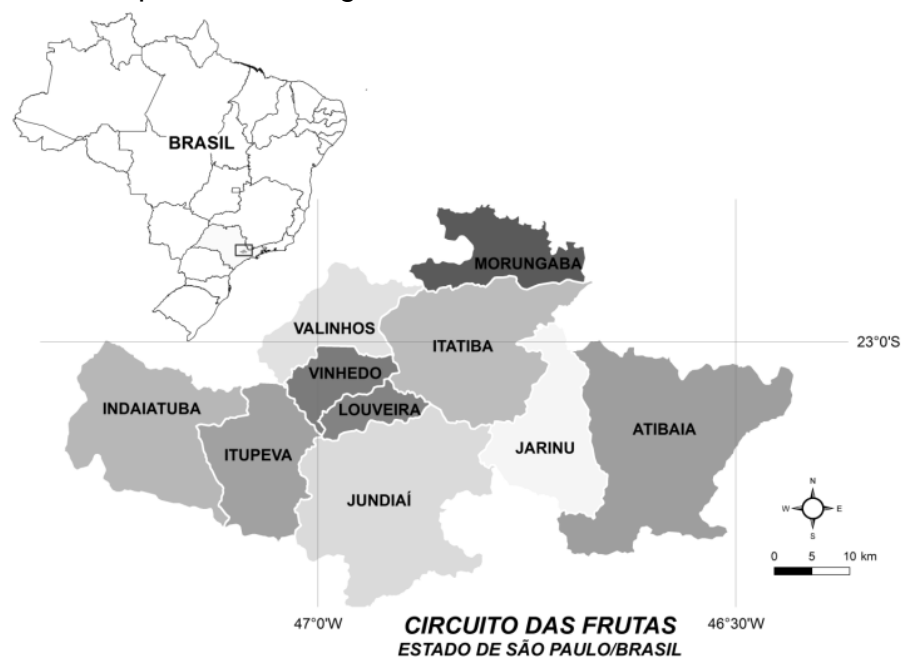

Figura 1. Mapa da localização do Circuito das Frutas - SP.

Elaborada pelas autoras, 2014.

\subsection{Circuito das Frutas: uma breve história}

Ao longo da segunda metade do século XIX a lavoura de café no Brasil passava por um enorme crescimento e à medida que afloravam os movimentos abolicionistas cresciam também as preocupações com a expansão da lavoura, já que a mão de obra 
cafeeira era formada por escravos. Uma alternativa para a substituição da mão de obra escrava foi a introdução do trabalho assalariado e com isso a mão de obra de imigrantes.

No Brasil, o estabelecimento das novas relações de produção combinou-se com a imigração de trabalhadores europeus, como recurso não só para constituir a força de trabalho necessária à cultura do café, mas também como recurso para pôr no lugar do trabalhador cativo um trabalhador livre cuja herança não fosse a escravidão. Mais de um milhão e seiscentos mil imigrantes vieram para o país no espaço de pouco mais de 30 anos, entre 1881 e 1913, a maioria para trabalhar como colonos nas fazendas de café (MARTINS, 1979, p. 22).

O colono imigrante que trabalhava nas lavouras de café do Estado de São Paulo combinava suas forças de trabalho com as da família, assim trabalhavam juntos, os homens, as mulheres e as crianças com mais de sete anos. Esse colono além de ter presente o caráter familiar do trabalho, também tinha na produção entre as linhas de café uma garantia ao sustento da família; plantava-se milho, feijão, arroz, batata, etc. Essa produção alimentava a família e algumas vezes era destinada à venda (o excedente) (MARTINS, 1979).

Para Martins (1979) a propriedade da terra era a condição de liberdade para estes imigrantes, visto que para libertarem-se da condição de colonos necessitavam tornarem-se proprietários da terra.

A classe dominante admitia que os imigrantes, via de regra, não teriam dinheiro suficiente para tornarem-se proprietários. No entanto, teoricamente (...), eles poderiam economizar dinheiro para essa finalidade trabalhando um certo tempo nas terras dos fazendeiros (MARTINS, 1979, p. 123).

A formação territorial dos municípios pertencentes ao Circuito das Frutas está ligada à chegada de imigrantes para a 
região de Campinas, que foram responsáveis pela inserção de diversas culturas na região, através da introdução de seus costumes. A constituição do Circuito das Frutas é decorrente da cultura e tradições desses imigrantes, levando-se em consideração fatores que vão desde o cultivo das frutas até a formação de uma política de desenvolvimento do agroturismo (BERNARDI, 2009).

Muitos avanços políticos, culturais, econômicos e sociais destes municípios são resultados do trabalho dos diversos imigrantes europeus (a maioria italianos) e japoneses. Os imigrantes vieram a essa região no início do século $\mathrm{XX}$ em busca de melhores oportunidades de trabalho nas fazendas de café, com algumas economias que já possuíam mais aquelas obtidas com o trabalho na lavoura, conseguindo dessa forma comprar o seu próprio pedaço de terra.

Os imigrantes, majoritariamente italianos, buscaram a região desde o início do século XX pela ampla oferta de trabalhos ligados à agricultura. Os imigrantes eram assalariados e logo conseguiram adquirir suas próprias terras, iniciando o cultivo de frutas como o figo, a goiaba e a uva na região. Houve também a preservação de seus costumes, destacando-se a crença religiosa, a realização de festas, a fabricação de vinhos, etc. (BERNARDI, 2009, p. 90).

A permanência dos imigrantes nestes municípios é importante para o entendimento da atual configuração do Circuito das Frutas, pois foram eles quem transformaram os municípios em referências no cultivo de frutas e na realização de festas e eventos relacionadas às produções das mesmas. A crença religiosa foi outra característica bastante importante, uma vez que surgiram diversas igrejas, aumentando o número de missas e festas religiosas de forma considerável. As festas religiosas que ocorriam nos municípios foram as responsáveis pelo surgimento de algumas festas das frutas, pois com a venda das frutas o dinheiro arrecadado era doado para a igreja, assim das festas religiosas houve a transformação para as festas do figo e da uva. (BERNARDI, 2009)

Porém, na década de 1980 com a crescente valorização das terras e especulação imobiliária, aliado aos problemas financeiros dos produtores dessa região, muitos agricultores optaram pela venda de suas propriedades. 
(...) a situação para os produtores de frutas da região tornou-se difícil devido aos poucos investimentos públicos no setor. Desta forma, muitas famílias que ainda mantinham as plantações, tiveram que vender suas terras e buscar novas formas de obtenção de renda na cidade. (...) os atuais produtores de frutas podem ser considerados vitoriosos por ainda conseguirem manter vivas as tradições rurais de seus antepassados em momentos com uma geração de renda tão baixa como a que ocorre recentemente. (...) mesmo que uma parcela dos imigrantes tenha ido trabalhar nos setores secundário e terciário, o marcante para os municípios, sem dúvida alguma, o trabalho dos imigrantes no setor primário, em especial com a fruticultura (BERNARDI, 2009, p. 92).

Com o intuito de dinamizar a região no que tange à fruticultura pensou-se no Circuito das Frutas como um estímulo para o aumento da produção e de renda por meio do turismo e do cultivo das tradições herdadas dos imigrantes.

A origem do Circuito das Frutas remonta a meados dos anos 1990, quando produtores rurais da região buscavam no desenvolvimento do turismo rural alternativas para a viabilização econômica de suas propriedades. Mas apenas em 2000 um grupo composto por 27 produtores reuniu-se para a constituição da Associação de Turismo Rural do Circuito das Frutas.

No final da década de 1990, nascia, em nossa região, uma nova alternativa de geração de renda para o meio rural: o Turismo Rural. Como fator de agregação de valor aos produtos rurais, bem como as próprias propriedades, esta modalidade de turismo tem sido vista, desde então, como uma interessante forma de fortalecer nosso meio rural, nossas propriedades e nossos proprietários. Da união de vários proprietários rurais que passaram a discutir a profissionalização e a organização do turismo rural na região de Jundiaí, nasceu, em 
outubro de 2000, a Associação de Turismo Rural do Circuito das Frutas (CIRCUITO DAS FRUTAS, 2012).

Com a organização da associação houve o apoio das prefeituras dos municípios participantes, e de entidades como o Serviço Brasileiro de Apoio às Micro e Pequenas Empresas SEBRAE/SP e Serviço Nacional de Aprendizagem do Cooperativismo - SESCOOP/SP. Na mesma época, o interesse do governo estadual no desenvolvimento de roteiros turísticos propiciou a condição necessária para que, em 2 de outubro de 2002, fosse oficialmente instituído o Polo Turístico do Circuito das Frutas (PREFEITURA MUNICIPAL DE JUNDIAí, 2009).

A área total dos municípios que compõem o Circuito das Frutas é de $2.318 \mathrm{~km}^{2}$, com população estimada em 1.070 .400 habitantes. O Circuito das Frutas está localizado numa região próxima à grande São Paulo (PREFEITURA MUNICIPAL DE JUNDIAÍ, 2009).

De acordo com Otani et al. (2012) os municípios que compõe o Circuito foram definidos de acordo com os critérios do Decreto e da Resolução Conjunta de 2004, estabelecido entre as Secretarias de Estado da Agricultura e Abastecimento e a da Ciência, Tecnologia, Desenvolvimento Econômico e Turismo. Dessa forma, com a Resolução, a inclusão de municípios deve respeitar as seguintes condições: existência de plantio de frutas no município com comprovada relevância na produção da agropecuária municipal; existência de plantio de frutas com comprovada relevância no valor da produção estadual de frutas; e o município deve ser limítrofe com os constantes do Projeto Circuito das Frutas.

\subsection{Levantamento e análise de dados sobre o Pronaf}

Em pesquisa de campo verificou-se que as informações das Casas da Agricultura dos municípios sobre as DAPs (Declaração de Aptidão ao Pronaf) emitidas nem sempre resultam no contrato com o Programa. Assim, para haver maior segurança nos dados sobre o Pronaf, optou-se por trabalhar com dados secundários fornecidos pela Secretaria de Agricultura Familiar, do Ministério do Desenvolvimento Agrário - SAF/MDA.

Dessa forma, para a análise estatística foram adquiridos dados referentes ao Pronaf a partir da Base de Dados de Crédito do Pronaf, da Secretaria da Agricultura Familiar -SAF, do MDA. Os dados do Pronaf foram registrados a partir do ano de 2003/2004 em 
duas modalidades: Custeio e Investimento para municípios do Brasil até o ano 2011/2012. Nestes dados, tem-se informação da Unidade Federativa a qual os municípios pertencem, no total, têm-se nove períodos agrícolas.

Assim, foi realizada uma análise estatística exploratória sobre os dados relativos ao volume de recursos do Pronaf liberados para os 10 municípios do Circuito das Frutas, nas modalidades custeio e investimento, comparando com o total de recursos liberados para o Brasil. Dessa forma, o objetivo da análise estatística foi avaliar o volume de valor financiado, na área agrícola, liberados para os 10 municípios paulistas em relação ao total financiado no estado de São Paulo e no Brasil.

Com o objetivo de juntar os 10 municípios em grupos por proximidade foi realizada a análise de cluster. As variáveis consideradas foram valores financiados e número de contratos, por modalidade e ano agrícola. Foi utilizado o método de Ward, que é um método que faz o agrupamento considerando as distâncias definidas abaixo:

$$
D_{K L}=\frac{\left\|V_{K}-V_{L}\right\|^{2}}{\frac{1}{N_{K}} \square \frac{1}{N_{L}}}
$$

$\mathrm{K}$ e $\mathrm{L}$ representam dois clusters (grupos) e $V_{i}$, representa a média das variáveis em questão (Valor financiado ou Número de contratos) no cluster i.

A análise de cluster foi feita em duas etapas:

- Considerando somente os 10 municípios, para avaliar qual deles recebeu mais recurso.

- Considerando todos os municípios do Estado de São Paulo. Em ambos os casos, os municípios foram classificados em 3 clusters, identificando desta forma municípios com menor investimento, médio e alto.

Realizou-se também uma análise descritiva para avaliar a proporção de valor financiado por modalidade para cada município em questão em relação ao total financiado no estado de São Paulo.

\section{O PROGRAMA NACIONAL DE FORTALECIMENTO DA AGRICULTURA FAMILIAR NO BRASIL: UMA REVISÃO SOBRE $O$ PRONAF}

O reconhecimento institucional da agricultura familiar no Brasil se deu, especialmente, a partir dos estudos realizados pela 
Fao (Food and Agriculture Organization) em conjunto com o Incra (Instituto Nacional de Colonização e Reforma Agrária) no início dos anos 1990. Os resultados desses estudos foram publicados num relatório em 1994 que abordava sobre as "Diretrizes de Política Agrária e Desenvolvimento Sustentável” para o Brasil. A partir disso, a categoria agricultor familiar passou a ter visibilidade no que tange às políticas públicas.

Dessa forma, quando analisamos as políticas públicas brasileiras, especialmente as políticas agrícolas voltadas à agricultura familiar, conclui-se que essa categoria começou a ser lembrada em 1994 a partir da criação do Provape (Programa de Valorização da Pequena Produção Rural). Esse Programa foi 0 passo inicial para a constituição, dois anos depois, do Pronaf.

Antes do Provape o agricultor familiar era considerado como mini produtor para se enquadrar no Manual de Crédito Rural (MCR). O agricultor familiar encontrava-se em duas situações que o prejudicavam, pois de um lado era obrigado a disputar crédito com os grandes produtores e, de outro lado, se via obrigado a seguir a mesma rotina das instituições financeiras para obter crédito cujo perfil era voltado ao grande produtor rural (BELIK, 2000).

Considerado como um programa de política agrícola diferenciada para a agricultura familiar, emergindo a partir do Decreto 1.946, de 28 de Junho de 1996, surgiu o Programa Nacional de Fortalecimento da Agricultura Familiar (Pronaf). Esse novo programa não seria apenas a simples diferenciação nas normas de crédito rural para "pequenos produtores".

O Pronaf foi fruto da organização e reivindicação dos trabalhadores rurais que, no final da década de 1980, faziam diversas pressões sobre o Estado. Com as organizações e mobilizações dos agricultores e as contribuições dos estudos realizados pela Fao e pelo Incra (1994 e 2000), se estabeleceu um novo caminho para as políticas públicas no meio rural.

Esse Programa emergiu com o objetivo de fornecer crédito e apoio institucional aos agricultores familiares que até então eram excluídos das políticas públicas existentes. Em 1996 contava apenas com ações relacionadas ao crédito de custeio, sendo que a ampliação do programa para as linhas de investimentos, infraestrutura e serviços municipais, capacitação e pesquisa, ocorreu a partir de 1997, quando o Pronaf passou a operar de forma integrada em todo território nacional.

Ao longo dos anos o Pronaf passou por algumas mudanças institucionais e financeiras, que serviram para melhorar 
o acesso desse Programa aos agricultores familiares. $O$ volume de recursos vem aumentando progressivamente desde 1997, significando uma possibilidade concreta de acesso ao crédito a um número maior de agricultores familiares, considerando-se os diferentes graus de inserção nos mercados e as diferentes regiões do país. Para o Plano Safra de 2013/2014 o volume de recursos disponíveis para a agricultura familiar foi de $R \$ 21$ bilhões.

As mudanças pelas quais o Pronaf passou fez com que houvesse uma abrangência maior do Programa em termos nacionais, porém ainda verifica-se uma limitação quanto à distribuição regional de recursos, bem como o acesso aos mesmos entre os diversos segmentos da agricultura familiar. A fim de comprovar essa tese, Aquino (2009) realizou um estudo sobre o Pronaf desde a sua criação em 1996 até 2008. Nesse estudo o autor revela o caráter desigual do Pronaf no que tange à distribuição dos recursos nas regiões do país e nos segmentos de agricultores familiares.

Para Cardozo, Muniz e Nascimento (2012) apesar das modificações que o Pronaf teve ao longo dos anos no intuito de melhorar e facilitar o seu acesso pelos diversos segmentos de agricultores familiares, esse Programa não conseguiu fugir da lógica bancária que rege a distribuição de crédito, qual seja, o mais capitalizado consegue maior participação nos recursos públicos, significando que mesmo num programa de crédito cujo objetivo principal seja o fortalecimento de todas as categorias de agricultores familiares, os recursos do Pronaf não são acessados pelo segmento menos capitalizado da agricultura familiar.

O Pronaf ainda não conseguiu se esquivar da lógica de distribuição de recursos do sistema bancário, que prefere aqueles com maior capacidade de garantir segurança de pagamento dos empréstimos realizados pelos bancos. No próprio relatório institucional do Pronaf (2002) consta que as instituições bancárias, mesmo as públicas, acabam adotando lógicas similares às privadas, os bancos são pouco adequados para liberar recursos às famílias sem condições de lhes oferecer garantias patrimoniais $e$ contrapartidas na tomada de empréstimos.

Assim, apesar de representar uma grande conquista da agricultura familiar no que tange às políticas públicas não há consenso sobre os impulsos que esse programa pode causar quanto à melhoria de renda e de vida dos agricultores. Pesquisas que avaliam o Pronaf mostraram que o programa apresenta resultados positivos, mas também negativos, sendo que alguns 
estudos demonstram até uma piora na situação dos beneficiários em relação aos não beneficiários (GUANZIROLI, 2007).

Nesse sentido, Mattei et al. (2007) verificaram que os impactos mais consistentes do Pronaf ocorrem no campo produtivo, principalmente sobre a produção agrícola, indicando que o Programa continua profundamente direcionado para 0 aumento da produção, uma vez que está centrado no pacote tecnológico da Revolução Verde.

Deve-se deixar claro que o Pronaf acarretou inquestionáveis efeitos positivos ao desenvolvimento rural brasileiro, como a contribuição para a melhoria das condições de produção, colaborando para o aumento na oferta de alimentos, o incremento da produtividade de alguns produtos, a geração e a ocupação de empregos, que se refletem positivamente em alguns indicadores econômicos e produtivos rurais (GAZOLLA e SCHNEIDER, 2013).

Apesar dos problemas verificados em relação ao Pronaf, é indiscutível que o Programa é a legitimação da importância de uma política de crédito e de fortalecimento para a agricultura familiar brasileira, categoria esta tão esquecida durante muitos anos.

\section{ANÁLISE DO PRONAF NOS MUNICÍPIOS DO CIRCUITO DAS FRUTAS}

Desde a sua implementação, em 1996, o Pronaf vem se consolidando ano a ano como o principal programa de crédito da agricultura familiar no Brasil. Percebe-se que a cada ano houve um aumento tanto do número de beneficiários, quanto do montante de recursos financeiros disponibilizados e aplicados no Programa.

Porém, ao se verificar a distribuição regional dos valores aplicados, nota-se que a região Sul do país foi e continua sendo a maior beneficiária do Pronaf. De acordo com Aquino (2009) a região Nordeste, onde se localiza praticamente metade dos 4,1 milhões dos estabelecimentos familiares do país, apenas obteve espaço na distribuição do crédito subsidiado a partir de 2004, quando passou à frente da região Sudeste, mas, ainda em 2007, voltou a perder novamente posição no ranking nacional. 
Tabela 1. Percentuais de valor financiado e contratos correspondentes ao total de valor financiado/número de contratos para cada Unidade Federativa (UF) sobre o total de valor financiado/número de contratos no Brasil por modalidade (2003/2004 a 2011/2012).

\begin{tabular}{|c|c|c|c|c|c|}
\hline \multicolumn{3}{|c|}{ Modalidade Custeio } & \multicolumn{3}{|c|}{ Modalidade Investimento } \\
\hline UF & $\begin{array}{c}\% \text { Valor } \\
\text { financiado }\end{array}$ & $\begin{array}{c}\% \text { Número } \\
\text { de } \\
\text { contratos }\end{array}$ & UF & $\begin{array}{c}\% \text { Valor } \\
\text { financiado }\end{array}$ & $\begin{array}{c}\% \text { Número } \\
\text { de } \\
\text { contratos }\end{array}$ \\
\hline$A C$ & 0.2594 & 0.4205 & $A C$ & 0.5757 & 0.3893 \\
\hline $\mathrm{AL}$ & 0.4517 & 0.7038 & $A L$ & 1.5720 & 3.9802 \\
\hline AM & 0.1528 & 0.0894 & $\mathrm{AM}$ & 0.9468 & 1.2570 \\
\hline AP & 0.0248 & 0.0437 & AP & 0.1704 & 0.1013 \\
\hline BA & 2.6802 & 3.9826 & BA & 5.6877 & 12.9733 \\
\hline CE & 1.1140 & 2.0486 & CE & 4.0274 & 10.1860 \\
\hline DF & 0.0373 & 0.0264 & DF & 0.0284 & 0.0053 \\
\hline ES & 3.1014 & 2.9248 & ES & 3.1490 & 0.9685 \\
\hline GO & 4.1339 & 2.8849 & GO & 3.0185 & 0.8251 \\
\hline MA & 1.6818 & 3.1623 & MA & 4.3656 & 8.1798 \\
\hline MG & 15.0550 & 12.4723 & MG & 11.4323 & 9.7573 \\
\hline MS & 0.8254 & 0.5485 & MS & 1.0018 & 0.3888 \\
\hline MT & 1.6593 & 1.1583 & MT & 3.4882 & 0.9444 \\
\hline PA & 1.7881 & 1.5178 & PA & 6.0860 & 5.0301 \\
\hline
\end{tabular}




\begin{tabular}{|c|c|c|c|c|c|}
\hline \multicolumn{3}{|c|}{ Modalidade Custeio } & \multicolumn{3}{|c|}{ Modalidade Investimento } \\
\hline PB & 0.2622 & 0.3486 & PB & 1.9835 & 5.4865 \\
\hline PE & 0.8881 & 0.8516 & PE & 4.0059 & 9.5126 \\
\hline $\mathrm{PI}$ & 0.7261 & 2.5040 & $\mathrm{PI}$ & 2.6150 & 6.7015 \\
\hline UF & $\begin{array}{c}\% \text { Valor } \\
\text { financiado }\end{array}$ & $\begin{array}{c}\% \text { Número } \\
\text { de } \\
\text { contratos }\end{array}$ & UF & $\begin{array}{c}\% \text { Valor } \\
\text { financiado }\end{array}$ & $\begin{array}{c}\% \text { Número } \\
\text { de } \\
\text { contratos }\end{array}$ \\
\hline PR & 15.8034 & 13.4669 & PR & 8.3657 & 2.7872 \\
\hline RJ & 1.2559 & 0.9193 & RJ & 0.2958 & 0.1595 \\
\hline $\mathrm{RN}$ & 0.7559 & 3.3082 & $\mathrm{RN}$ & 1.7264 & 4.1130 \\
\hline RO & 1.5786 & 1.7036 & RO & 2.9960 & 1.0985 \\
\hline $\mathrm{RR}$ & 0.0371 & 0.0565 & $\mathrm{RR}$ & 0.2794 & 0.2541 \\
\hline RS & 26.2878 & 29.3505 & RS & 16.4728 & 6.6001 \\
\hline SC & 12.8291 & 10.6602 & $\mathrm{SC}$ & 8.7897 & 2.6575 \\
\hline SE & 0.7552 & 1.3461 & SE & 1.2420 & 3.4514 \\
\hline SP & 5.3000 & 2.9687 & SP & 3.6584 & 0.9011 \\
\hline TO & 0.5553 & 0.5317 & TO & 2.0191 & 1.2902 \\
\hline
\end{tabular}

Fonte: Dados da Pesquisa, 2012.

Através da tabela 1 , verifica-se a tendência da região Sul do país na concentração dos recursos, sobretudo o estado do Rio Grande do Sul. No período de 2003/2004 a 2011/2012 esse estado foi o que mais recebeu recursos, tanto para a modalidade custeio quanto para a modalidade investimento. Ao verificarmos a porcentagem de números de contratos nota-se que o estado da Bahia superou o estado do Rio Grande do Sul, dessa forma percebese que nesse estado há mais recursos sendo aplicados, porém menos agricultores que usufruem dos mesmos, comparado com o estado da Bahia. A distribuição dos recursos de custeio, em todo o 
período, mostrou-se mais concentrada do que a dos recursos da linha investimento.

Assim, para a modalidade custeio, os estados de Minas Gerais, Paraná, Santa Catarina e Rio Grande do Sul apresentaram maior proporção de números de contratos e valor financiado. O estado de São Paulo representa em torno de $5 \%$ dos valores financiados e $3 \%$ de números de contratos em relação ao total nacional.

Em relação à modalidade investimento, identificou-se que há mais unidades federativas com proporções maiores. Desta forma, nesta modalidade, a distribuição de recursos é mais homogênea e menos concentrada. No caso, $3,7 \%$ dos valores financiados são destinados ao estado de São Paulo, que é responsável por $1 \%$ dos contratos.

O estado de São Paulo no período de 2003/2004 a $2011 / 2012$, para a modalidade custeio, foi o quarto que mais obteve recursos e mais apresentou número de contratos. Porém, quando se observa a modalidade investimento, o estado de São Paulo ocupou a $20^{\underline{a}}$ posição para o número de contratos do Pronaf. Tal fato significa que os agricultores do estado de São Paulo pouco utilizam o crédito do Pronaf para realizarem investimentos em suas propriedades, preferindo o uso desse crédito para custear sua produção.

Souza e Valente Jr. (2006) já haviam identificado a pequena participação do estado de São Paulo, principalmente para a modalidade investimento, verificando que durante o período de 2001 a 2004 esse Estado ficou entre a $7^{\underline{a}}$ e $8^{\underline{a}}$ classificação em todos os anos analisados.

Ao se analisar especificamente a distribuição de créditos do Pronaf nos municípios que pertencem ao Circuito das Frutas, verifica-se que essa região é pouco representativa dentro do estado em termos de acesso ao crédito do Pronaf. Tal fato pode ser observado na tabela 2, onde são apresentados os percentuais de valor financiado e contratos correspondentes ao total de valor financiado/número de contrato para os 10 municípios sobre o total de valor financiado/número de contrato no estado de São Paulo por período (ano agrícola) e modalidade. 
Tabela 2 - Percentuais de valor financiado e contratos correspondentes ao total de valor financiado/número de contrato sobre o total de valor financiado/número de contrato no Estado de São Paulo por período (ano agrícola) e modalidade (municípios do Circuito das Frutas).

\begin{tabular}{|c|c|c|c|}
\hline Ano Agrícola & Modalidade & $\begin{array}{c}\% \text { Valor } \\
\text { financiado }\end{array}$ & $\begin{array}{l}\% \text { Número de } \\
\text { contratos }\end{array}$ \\
\hline \multirow{2}{*}{$2003 / 2004$} & Custeio & 1.5247 & 0.98953 \\
\hline & Investimento & 0.29675 & 0.29350 \\
\hline \multirow{2}{*}{$2004 / 2005$} & Custeio & 1.57108 & 1.00591 \\
\hline & Investimento & 0.18451 & 0.12070 \\
\hline \multirow{2}{*}{$2005 / 2006$} & Custeio & 1.16556 & 0.88253 \\
\hline & Investimento & 0.59566 & 0.48214 \\
\hline \multirow{2}{*}{$2006 / 2007$} & Custeio & 1.54467 & 1.21290 \\
\hline & Investimento & 0.51762 & 0.35006 \\
\hline \multirow{2}{*}{$2007 / 2008$} & Custeio & 1.33744 & 0.96204 \\
\hline & Investimento & 0.77256 & 0.63830 \\
\hline \multirow{2}{*}{$2008 / 2009$} & Custeio & 1.49456 & 1.18357 \\
\hline & Investimento & 3.12821 & 1.79680 \\
\hline \multirow{2}{*}{$2009 / 2010$} & Custeio & 1.35853 & 1.13965 \\
\hline & Investimento & 2.07865 & 1.33934 \\
\hline \multirow{2}{*}{$2010 / 2011$} & Custeio & 1.30674 & 1.10198 \\
\hline & Investimento & 1.77664 & 1.20236 \\
\hline \multirow{2}{*}{$2011 / 2012$} & Custeio & 1.17071 & 1.05404 \\
\hline & Investimento & 1.11306 & 0.93825 \\
\hline
\end{tabular}

Fonte: Dados da Pesquisa, 2012. 
Os municípios do Circuito das Frutas confirmam a tendência do estado de São Paulo, qual seja, a maior distribuição e acesso ao crédito para a modalidade custeio, havendo assim uma menor concentração dessa modalidade entre os agricultores familiares, sendo que a maior porcentagem financiada para custeio no Circuito das Frutas foi na safra 2006/2007. Para a modalidade investimento observou-se um aumento significativo na safra 2008/2009 comparado às safras anteriores. Porém na safra seguinte (2009/2010) a porcentagem de valor financiado para a modalidade investimento caiu cerca de $66 \%$.

Foram realizadas entrevistas com agrônomos das Casas da Agricultura dos municípios para haver uma melhor compreensão sobre a pequena participação dos agricultores familiares dessa região em relação ao acesso ao Pronaf, tanto para custeio quanto para investimento. Esses agentes locais, em sua maioria, acreditam que os agricultores do Circuito das Frutas, até mesmo pela história de formação da região, não possuem o "costume" em adquirir financiamento, muitas vezes por desconfiança e/ou medo em contrair uma dívida.

Os agricultores daqui preferem guardar um pouco de dinheiro para investir na propriedade, até mesmo nem investir do que ficar endividado. É uma cultura deles, porque os pais deles já faziam assim, aí eles também preferem fazer igual (Entrevista, Sr. J.B.S., engenheiro agrônomo Casa da Agricultura de Jarinu, 2012).

Faz-se necessário esclarecer que o estado de São Paulo possui historicamente uma agricultura pujante baseada, sobretudo, no agronegócio onde se destacam a produção de café, cana-deaçúcar e laranja. Constata-se que no meio rural paulista houve um processo contínuo de acumulação capitalista, o que pode ser corroborado através do Índice de Gini, que em 1985 era de 0,770 e em 2006 foi de 0,804, aumentando assim a concentração de terras neste Estado.

De acordo com os dados do Censo Agropecuário de 2006, a agricultura familiar no estado de São Paulo representava $66 \%$ dos estabelecimentos rurais, ocupando uma área de apenas 15\%. Ou seja, dentre os estados que mais receberam créditos do Pronaf, o estado de São Paulo é o que possui menor número de 
estabelecimentos rurais familiares (Santa Catarina e Bahia: $87 \%$, Rio Grande do Sul: $86 \%$, Paraná: $82 \%$, Minas gerais: $79 \%$ ). Além disso, percebe-se também que grande parte dos recursos do Pronaf no estado de São Paulo reafirmou a tendência de financiamento da agricultura voltada para o agronegócio, uma vez que segundo dados do Bacen em 2012, os recursos do Pronaf para custeio foram direcionados: $17 \%$ para o café; $15,7 \%$ milho; $5,8 \%$ cana-de-açúcar; $5,4 \%$ soja e $52 \%$ para outras culturas. Ou seja, no estado de São Paulo, assim como em outros estados, verifica-se que o crédito do Pronaf direciona-se para o custeio de culturas voltadas à exportação, ou commodities agrícolas, que são pouco presentes na região do Circuito das Frutas.

Ao se analisar cada município do Circuito das Frutas verificou-se uma distribuição desigual entre eles, ou seja, há municípios como Vinhedo e Valinhos cujos agricultores pouco têm acessado os recursos do Pronaf, tanto a modalidade investimento quanto a modalidade custeio, em contrapartida o município de Louveira foi o que mais apresentou agricultores que acessaram o Pronaf. Esse fato pode estar relacionado com a crescente urbanização e perda de área rural para a formação de condomínios fechados em Vinhedo e Valinhos.

O município de Louveira foi o que apresentou maior valor financiado e número de contratos nos 9 períodos analisados para a modalidade custeio. Já para a modalidade investimento o município de Jarinu apresentou um pico de valor financiado e de número de contratos em 2008/2009 e o município de Itatiba apresentou um pico de valor financiado em 2010/2011.

Realizando a análise de cluster no Circuito das Frutas, notase que dentre os 10 municípios foi possível agrupá-los considerando 3 clusters, descritos a seguir:

- Cluster 1: menor recurso recebido: valor financiado e número de contratos

- $\quad$ Cluster 2: médio valor financiado e número de contratos

- Cluster 3: maior valor financiado e número de contratos

A tabela 3 apresenta a frequência (número de períodos/safra agrícola) que cada município foi classificado em determinado cluster, de acordo com o valor financiado, conforme a modalidade custeio.

Tabela 3. Frequência (número de períodos) e classificação dos municípios em cluster, conforme o valor financiado, modalidade custeio (2003/2004 a 2011/2012). 


\section{Municípios}

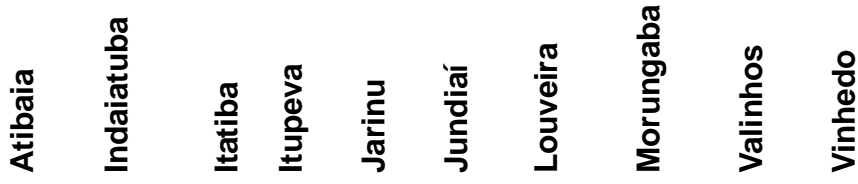

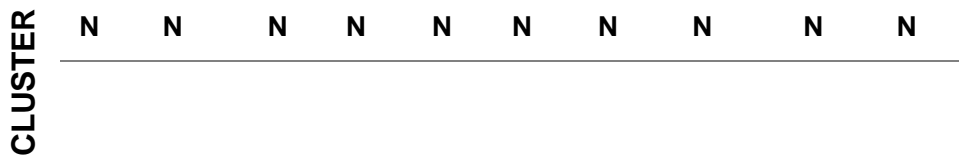

$\begin{array}{lllllllllll}1 & . & 4 & 7 & 5 & 5 & 1 & . & 9 & 8 & 9 \\ 2 & 9 & 5 & 2 & 4 & 4 & 8 & 3 & . & . & . \\ 3 & . & . & . & . & . & . & 6 & . & 1 & .\end{array}$

Fonte: Dados da Pesquisa, 2012.

Nota-se que em todos os períodos (ano agrícola) o município de Atibaia é classificado sempre no cluster 2, ou seja, possui um médio valor financiado e número de contratos, se comparado aos demais municípios do Circuito. Já o de Vinhedo e Morungaba estão sempre classificados no cluster 1 , significando os municípios cujos agricultores menos adquiriram recursos do Pronaf para a modalidade custeio, tanto em valor financiado, quanto em número de contratos. Nesse mesmo caminho está o município de Valinhos, sendo classificado no cluster 1 em 8 períodos, porém esse município se difere dos outros dois anteriormente citados pois aparece também classificado no cluster $3 \mathrm{em} 1$ período, o que significa que nesse município durante um determinado ano agrícola houve aumento no valor contratado para a modalidade custeio. Porém essa situação não foi recorrente, tratando-se de um fato isolado.

O município de Louveira é classificado no cluster 3 em 6 períodos (ano agrícola) e em 3 no cluster 2, confirmando assim que esse município foi o que teve mais agricultores que acessaram os 
recursos do Pronaf modalidade custei, nos 9 períodos analisados (2003/2004 a 2011/2012) dentre os 10 municípios.

Para a modalidade investimento o comportamento do município de Louveira não difere muito em relação à modalidade custeio, pois foi classificado em 4 períodos no cluster 3 , ou seja, em 4 anos agrícolas foi o município cujos agricultores mais acessaram os recursos do Pronaf (Tabela 4).

Tabela 4. Frequência (número de períodos) e classificação dos municípios em cluster, conforme o valor financiado, modalidade investimento (2003/2004 a 2011/2012).

\section{Municípios}

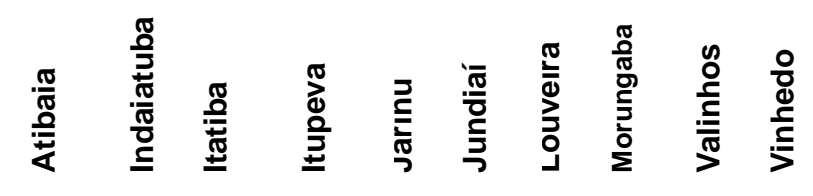

\begin{tabular}{|c|c|c|c|c|c|c|c|c|c|c|}
\hline 采 & $\mathbf{N}$ & $\mathbf{N}$ & $\mathbf{N}$ & $\mathbf{N}$ & $\mathbf{N}$ & $\mathbf{N}$ & $\mathbf{N}$ & $\mathbf{N}$ & $\mathbf{N}$ & $\mathbf{N}$ \\
\hline 1 & 7 & 4 & 3 & 5 & 5 & 3 & 3 & 5 & 6 & 4 \\
\hline 2 & 2 & 2 & 2 & 2 & 2 & 3 & . & 3 & & \\
\hline 3 & . & 1 & 2 & . & 1 & 1 & 4 & . & & . \\
\hline
\end{tabular}

Fonte: Dados da Pesquisa, 2012.

Nota-se que para a modalidade investimento, a classificação dos municípios nos clusters fica menos nítida, ou seja, fica mais difícil dizer em que cluster cada município é classificado em mais períodos (ano agrícola). Isto ocorre devido à concentração existente na modalidade investimento, sendo que a modalidade custeio ocorre uma maior distribuição entre os agricultores.

Em relação ao número de contratos (modalidade custeio), a situação não difere muito do valor financiado, permanecendo o 
município de Louveira como aquele que mais teve contratos entre os agricultores familiares, uma vez que aparece classificado em 7 períodos no cluster 3 (maior número de contratos) e em 2 períodos no cluster 2 (médio número de contratos). Os municípios de Valinhos, Vinhedo, Morungaba e Itatiba foram os que apresentaram os menores números de contratos nos 9 períodos analisados (2003/2004 a 2011/2012).

A tabela 5 apresenta a frequência (número de períodos) que cada município foi classificado em cada cluster conforme o número de contratos para a modalidade custeio.

Tabela 5. Frequência (números e períodos) e classificação dos municípios em cluster, conforme número de contratos, modalidade custeio (2003/2004 a 2011/2012).

\section{Municípios}
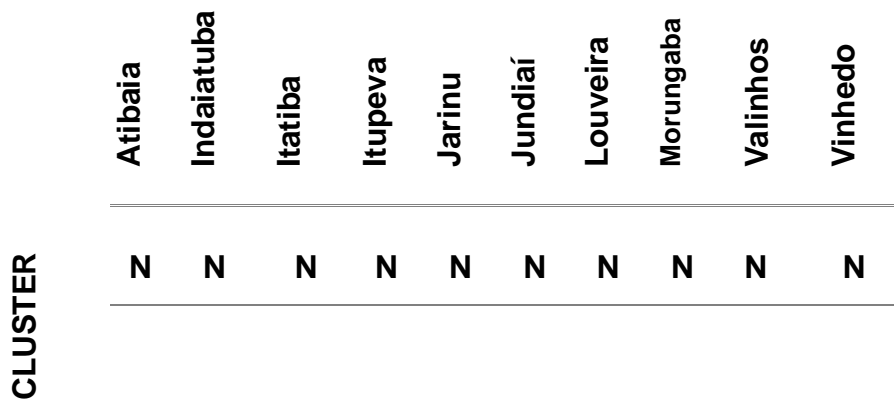

$\begin{array}{lllllllllll}1 & 1 & 4 & 8 & 7 & 5 & 2 & . & 9 & 8 & 8 \\ 2 & 4 & 4 & 1 & 2 & 4 & 6 & 2 & . & . & . \\ 3 & 4 & 1 & . & . & . & 1 & 7 & . & 1 & .\end{array}$

Fonte: Dados da Pesquisa, 2012.

Em relação à modalidade investimento nota-se através da Tabela 6 que os municípios do Circuito das Frutas possuem baixo número de contratos, uma vez que, com exceção do município de Jarinu, todos os outros foram classificados no cluster 1 . 
Tabela 6 - Frequência (números e períodos) e classificação dos municípios em cluster, conforme número de contratos, modalidade Investimento (2003/2004 a 2011/2012).

\section{Municípios}

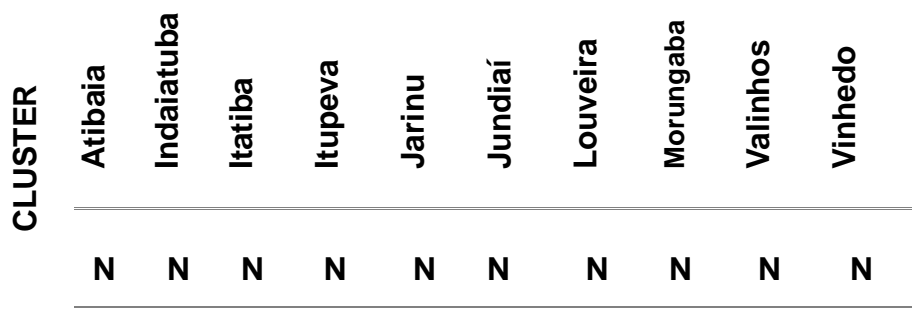

$\begin{array}{lllllllllll}1 & 9 & 7 & 7 & 7 & 7 & 7 & 7 & 8 & 6 & 4 \\ 2 & . & . & . & . & 1 & . & . & . & . & . \\ 3 & . & . & . & . & . & . & . & . & . & .\end{array}$

Fonte: Dados da Pesquisa, 2012.

Através das análises de cluster realizadas nos 10 municípios que fazem parte do Circuito das Frutas pode-se concluir que essa região tanto em relação ao valor financiado, quanto em relação ao número de contratos, para as modalidades custeio e investimento, possui pouca significância para o crédito do Pronaf, uma vez que a maioria dos municípios estava classificada no cluster 1 , que representa o menor recurso recebido.

Quando se compara o volume de recursos contratados pelos agricultores familiares dos municípios do Circuito das Frutas em relação ao estado de São Paulo, percebe-se que essa região não é significativa dentro do estado, em relação ao volume de crédito e número de contratos, tanto para a modalidade custeio, quanto para a modalidade investimento. Isto porque nenhum dos 10 municípios analisados foi classificado no cluster 3 (maior recurso recebido, para valor financiado e número de contratos). 
Tal fato pode ser corroborado através da Tabela 7 , onde são apresentados os percentuais dos valores financiados e dos contratos correspondentes ao total de valores financiados/números de contratos para os 10 municípios sobre o total de valores financiados/números de contratos no estado de São Paulo por período (ano agrícola) e modalidades.

Tabela 7 - Percentuais de valor financiado e contratos correspondentes ao total de valor financiado/número de contrato sobre o total de valor financiado/número de contrato no Estado de São Paulo por período (ano agrícola) e modalidade (municípios do Circuito das Frutas).

\begin{tabular}{clcc}
$\begin{array}{c}\text { Ano } \\
\text { Agrícola }\end{array}$ & Modalidade & $\begin{array}{c}\text { \% Valor } \\
\text { financiado }\end{array}$ & $\begin{array}{c}\text { \% Número de } \\
\text { contratos }\end{array}$ \\
\hline $2003 / 2004$ & Custeio & 1.5247 & 0.98953 \\
& Investimento & 0.29675 & 0.29350 \\
$2004 / 2005$ & Custeio & 1.57108 & 1.00591 \\
& Investimento & 0.18451 & 0.12070 \\
$2005 / 2006$ & Custeio & 1.16556 & 0.88253 \\
& Investimento & 0.59566 & 0.48214 \\
& Custeio & 1.54467 & 1.21290 \\
$2006 / 2007$ & Investimento & 0.51762 & 0.35006 \\
& Custeio & 1.33744 & 0.96204 \\
$2007 / 2008$ & Investimento & 0.77256 & 0.63830 \\
& Custeio & 1.49456 & 1.18357 \\
$2008 / 2010$ & Custeio & 1.35853 & 1.79680 \\
& Investimento & 3.12821 & 1.13965 \\
\hline \multirow{2}{*}{2009} & & &
\end{tabular}




\begin{tabular}{clcc}
\hline $\begin{array}{c}\text { Ano } \\
\text { Agrícola }\end{array}$ & Modalidade & $\begin{array}{c}\text { \% Valor } \\
\text { financiado }\end{array}$ & $\begin{array}{c}\text { \% Número de } \\
\text { contratos }\end{array}$ \\
\hline & Investimento & 2.07865 & 1.33934 \\
$2010 / 2011$ & Custeio & 1.30674 & 1.10198 \\
& Investimento & 1.77664 & 1.20236 \\
& Custeio & 1.17071 & 1.05404 \\
\hline
\end{tabular}

Fonte: Dados da Pesquisa, 2012.

Apesar da maior parte dos agricultores dos municípios serem considerados familiares e mesmo que a maioria das propriedades possua área entre 2 e 50 ha, sendo que nesse intervalo a concentração das propriedades está entre 2 e 5 ha, com destaque para a produção de frutas e também de hortaliças (SÃO PAULO: SAA/CATI/IEA, 2008.), verificou-se por meio dos dados obtidos junto à SAF/MDA que tanto o valor financiado, quanto a quantidade de contratos nos municípios é pequena frente ao volume de recursos financiados no estado de São Paulo.

Percebe-se dessa forma que os agricultores familiares desses municípios preferem aplicar recursos próprios, ou mesmo não investirem em suas propriedades a terem que acessar uma linha de financiamento rural, ainda que esse financiamento seja através do Pronaf, que com o passar dos anos vem diminuindo a taxa de juros e aumentando o volume de recursos destinados aos agricultores.

\section{CONSIDERAÇÕES FINAIS}

$\mathrm{Na}$ análise do Pronaf verificou-se que diante do estado de São Paulo, nos municípios do Circuito das Frutas tanto o número de contratos, quanto o volume de créditos é pequeno. Tal fato significa que nessa região esse programa não é muito acessado entre os agricultores. Um dos motivos para isso está relacionado ao fato de que esses agricultores possuem receio em contrair uma dívida, sendo que muitos optam por investir na propriedade com recursos próprios ou mesmo não investir. 
Essa tendência na região estudada pode ser explicada também pelas exigências e burocracias bancárias que dificultam o acesso dos agricultores ao Pronaf. Está também relacionada ao fato de que tradicionalmente a maior parte dos recursos do Pronaf financia a produção de grãos e outras commodities agrícolas, produtos cuja produção não é expressiva nos municípios analisados. Dessa forma, ao ser verificado o número de contratos e o volume de crédito do Pronaf nesses municípios, percebeu-se que após 17 anos da implementação desse programa ainda são poucos os agricultores que 0 acessam.

A título de conclusão, nota-se que a análise de um programa como o Pronaf nos municípios do Circuito das Frutas demonstrou que o mesmo não possui impacto na economia dos municípios.

\section{AGRADECIMENTOS}

Agradecemos à Fundação de Amparo à Pesquisa do Estado de São Paulo - FAPESP pelo auxílio financeiro, através da bolsa de pós-doutorado (2010-2013) e da reserva técnica para o desenvolvimento da pesquisa: $\mathrm{O}$ impacto das políticas públicas nos municípios do Circuito das Frutas-SP, que originou este artigo. 


\section{REFERÊNCIAS}

AQUINO, J. R. Avanços e limites da política de crédito do Pronaf no Brasil (1996-2008): uma reflexão crítica. Anais... In: XLVII Congresso da Sociedade Brasileira de Economia, Administração e Sociologia Rural. Porto Alegre-RS: UFRGS, 2009.

BELIK, W. Pronaf: avaliação da operacionalização do programa. In: CAMPANHOLA, C. e GRAZIANO DA SILVA, J. (Orgs.). O Novo Rural Brasileiro - Políticas Públicas. Jaguariúna: Embrapa, vol. 4, p. 93-116, 2000.

BERNARDI, A. Estratégias de desenvolvimento local e regional: um estudo sobre o Circuito das Frutas e sua articulação com a Região Metropolitana de Campinas (SP). 2009. 182p. Dissertação (Mestrado em Geografia) - Instituto de Geociências, Universidade Estadual de Campinas, Unicamp, SP, 2009.

CARDOSO, J. G, MUNIZ, A. L. P. e NASCIMENTO, C. Potencialidades e desafios dos apoios financeiros alternativos para a agricultura familiar por meio das compras governamentais: o caso do PAA e do PNAE. Anais... In: 50 Congresso da Sociedade Brasileira de Economia, Administração e Sociologia Rural. Vitória-ES: UFES, 2012.

CIRCUITO DAS FRUTAS PAULISTA. Associação de Turismo Rural do Circuito das Frutas. Disponível em: http://www.circuitodasfrutas.com.br/php2/index.php. Acesso em: 07/06/2012.

GAZOLLA, M.; SCHNEIDER, S. Qual "Fortalecimento" da Agricultura Familiar? Uma análise do Pronaf crédito de custeio e investimento no Rio Grande do Sul. Revista de Economia e Sociologia Rural, vol. 51, n. 1, jan/mar, 2013. p. 45-68.

GUANZIROLI, C. E. Pronaf dez anos depois: resultados e perspectivas para o desenvolvimento rural. Revista de Economia e Sociologia Rural, Rio de Janeiro, vol. 45, n. 02, abr/jun. 2007. p. 301-328.

MARTINS, J. S. O cativeiro da terra. 2.ed. São Paulo: Ciências Humanas, 1979. 157p. 
MATTEI, L. et. al. Uma análise dos impactos do Pronaf sobre as economias locais nas regiões Nordeste, Sudeste e Norte do Brasil. Anais... In: XLV Congresso da Sociedade Brasileira de Economia, Administração e Sociologia Rural. Londrina-PR: UEL, 2007.

OTANI, M. N., FREDO, C. E., RAMOS, R. C. Circuito das Frutas Paulista: caracterização socioeconômica. Informações Econômicas, v. 42, n. 3, maio/jun. 2012. p. 50-64.

PREFEITURA MUNICIPAL DE JUNDIAÍ. Secretaria Municipal de Agricultura e Abastecimento. Emissão Mercosul: Produtos de Exportação - Circuito das Frutas - Turismo Rural. 2009. Disponível em: <http://www.selosefilatelia.com/PastaLancamentos09/016.html>. Acesso em: 12/05/2010.

SÃO PAULO (ESTADO) SECRETARIA DE AGRICULTURA E ABASTECIMENTO. COORDENADORIA DE ASSISTÊNCIA TÉCNICA INTEGRAL. INSTITUTO DE ECONOMIA AGRÍCOLA. Levantamento censitário de unidades de produção agrícola do Estado de São Paulo - LUPA 2007/2008. São Paulo: SAA/CATI/IEA, 2008. Disponível em: <http://www.cati.sp.gov.br/projetolupa>. Acesso em: 15/09/2011.

SOUZA, J. M. P. e VALENTE, J. R. A. S. Análise das liberações dos recursos do Pronaf - descentralização das aplicações do crédito rural. Anais... In: XLIV Congresso da Sociedade Brasileira de Economia, Administração e Sociologia Rural. Fortaleza-CE: UFCE. 2006. 